\title{
Revista
}

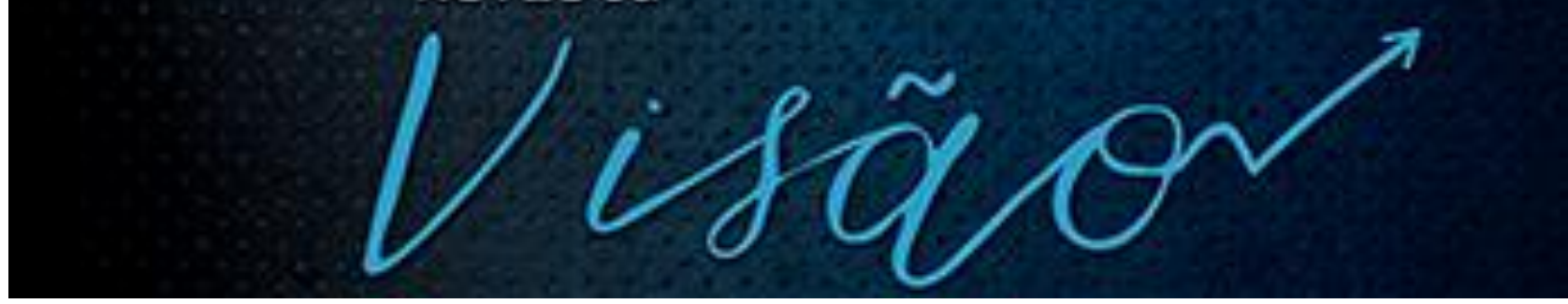

\section{AS ÂNCORAS DE CARREIRA DA GERAÇÃO Z}

\section{GENERATION Z CARRER ANCHORS}

\author{
Monique Chaicoski ${ }^{1}$ \\ https://orcid.org/0000-0003-4159-9227 \\ Josiéli Varela Forlin ${ }^{2}$ \\ https://orcid.org/0000-0002-5877-8953 \\ Joel Haroldo Baade ${ }^{3}$ \\ https://orcid.org/0000-0001-7353-6648
}

Recebido em: 17 dez. 2020 Aceito em: 18 nov. 2021

Como citar este artigo: CHAICOSKI, M.; FORLIN, J. V.; BAADE, J. H. AS ÂNCORAS DE CARREIRA DA GERAÇÃO Z: GENERATION Z CARRER ANCHORS. Revista Visão: Gestão Organizacional, Caçador (SC), Brasil, v. 10, n. 2, p. 115-127, 2021. DOI: 10.33362/visao.v10i2.2455. Disponível em: https://periodicos.uniarp.edu.br/index.php/visao/article/view/2455.

Resumo: Contextualizar as âncoras de carreiras de jovens da geração $Z$ em formação profissional. O desenvolvimento de carreira é fundamental para qualquer profissional com muitas variáveis, que comandam o comportamento para que se tenha uma compreensão de quais os valores que movem o mundo profissional. Essas âncoras são pilares que orientam as decisões de carreira de cada indivíduo. O teste âncoras de carreira vem com o objetivo fazer com que cada jovem profissional descubra quais delas têm maior peso em sua experiência para o trabalho. O presente estudo vem com a intenção de analisar e comparar as percepções destes 100 jovens respondentes da geração $Z$ sobre carreira e vida profissional. O método de pesquisa utilizado foi o de levantamento de campo. Através de uma pesquisa descritiva quantitativa dos dados. Utilizar-se-á como base de análise o instrumento (inventário de âncoras de carreira) proposto por Schein (1996). Com base nos resultados dos 100 jovens respondentes, as principais âncoras de carreira são: Análise da dimensão competência técnica-funciona (média 3,49); Análise da dimensão segurança e estabilidade (média 3,58); Análise da dimensão senso de dever e dedicação a uma causa (média 3,57); Análise da dimensão desafio puro (média 3,46). Palavras-Chave: Ancora de carreira. Geração Z. Teste. Formação.

\footnotetext{
${ }^{1}$ Monique Chaicoski aluna da graduação em Administração pela Universidade Alto Vale do Rio do Peixe - UNIARP. Endereço: Rua Maturino Borges Luz, 50. Caçador/SC. E-mail: moniquechaicoski@hotmail.com.

2 Josiéli Varela Forlin. Professora dos Cursos de Psicologia e Administração da UNIARP. Mestranda do Programa de Mestrado em Desenvolvimento e Sociedade da UNIARP - Caçador. Psicóloga. CRP 12/04932. Endereço: Rua Victor Baptista Adami, 505 - apto 102. Caçador/SC. E-mail: josieli.varela@uniarp.edu.br.

3 Joel Haroldo Baade. Doutor. Docente dos Programas de Pós-Graduação em Desenvolvimento e Sociedade e Profissional em Educação Básica da UNIARP. E-mail: baadejoel@uniarp.edu.br.
} 
Abstract: Contextualize the anchors of the careers of young generation $\mathrm{Z}$ in professional training. Career development is fundamental for any professional with many variables, who command the behavior so that one has an understanding of what values move the professional world. These anchors are the pillars that guide each individual's career decisions. The career anchors test comes with the objective of making each young professional discover which ones have greater weight in their work experience. This study comes with the intention of analyzing and comparing the perceptions of these 100 young generation $Z$ respondents about their career and professional life. The research method used was the field survey. Through a descriptive quantitative research of the data. The instrument (inventory of career anchors) proposed by Schein (1996) will be used as the basis for analysis. Based on the results of the 100 young respondents, the main career anchors are: Analysis of the technical competence-function dimension (average 3.49); Analysis of the security and stability dimension (average 3.58); Analysis of the dimension sense of duty and dedication to a cause (average 3.57); Analysis of the pure challenge dimension (mean 3.46).

Keywords: Career anchor. Generation Z. Test. Training.

\section{INTRODUÇÃO}

Entender as gerações e nomeá-las torna-se um hábito cada vez mais comum. Ao invés de dividi-los por idade, sexo e renda, a classificação por gerações é definida como a mais correta para definição do indivíduo, independente de mudanças pessoais, faixas etárias ou econômicas (BOLDRINI; LUCENA, 2014; SERRANO, 2010).

Estudando tais gerações classificamos por indivíduos que nasceram na mesma época ou vivenciaram um mesmo contexto histórico, o qual determinam atitudes e comportamentos, impactando de certa forma na evolução da sociedade. Nos dias de hoje, estudos apontam quatro gerações existentes, sendo elas: Baby Boomers (nascidos entre 1946 e 1964), Geração X (nascidos entre 1961 e 1977), Geração Y (nascidos entre 1978 e 1992), Geração Z (nascidos entre 1993 e 2009) e a mais recente, Geração Alpha (nascidos a partir de 2010). Mas o foco desse artigo vem para a Geração Z, podendo assim determinar fatores que determinam as âncoras de carreira dessa geração (KULLOCK, 2010).

Diante destes pontos, na qual seus representantes são aqueles que estão finalizando sua fase adolescente e escolar, a nossa geração Z, muitos dos quais já estão ingressando na universidade e na sua trajetória profissional. Construir uma carreira exige decisões e atitudes, bem como, observa-se que a escolha da futura profissão é uma tarefa importante inserida na fase da adolescência, considerada um período de mudanças e incertezas, o jovem começa a perceber suas responsabilidades e assumi-las (RODRIGUES; BORMIO, 2008; VELOSO et al., 2011).

De acordo com a revista Veja (2014), em pesquisa com 17.000 estudantes de São Paulo-SP, 62\% dos pesquisados nas instituições públicas já têm uma carreira/profissão em 
mente. Todavia, nas instituições particulares esse indicador recua para 53\%. Então é de suma importância refletirmos sobre nossos jovens estarem atendendo perspectivas globais ou não sobre aspirações de carreira (VEJA, 2014).

Percebe-se a necessidade das âncoras de carreira como auxílio aos jovens da Geração $Z$ de forma a dar objetivos mais específicos e delimitados na busca por sua carreira de sucesso. Com este trabalho espera-se contribuir para que a escolha profissional dos jovens seja auxiliada de forma responsável, profissional e eficaz para que seja a mais assertiva possível de acordo com suas escolhas e personalidade. A importância deste trabalho vem de encontro com o fato de que cada vez mais pessoas estão sofrendo com os diversos problemas do seu trabalho, desde não se encaixar em suas escolhas até problemas psicológicos devido a isso. Com as âncoras de carreira é possível alinhar o profissional certo à profissão correta.

Perante estes dados, torna-se extremamente importante refletir sobre o novo ambiente de trabalho desses jovens e entender suas grandes ambições de carreira. Com isso, essa pesquisa tem como problema: Quais as âncoras de carreira da geração Z? (MENDES, 2012).

\section{A GERAÇÃO Z}

A geração Z surgiu após a geração Y, estes nascidos a partir do ano de 1993 (LEVENFUS, 2002; FAGUNDES, 2011). Essa geração vive uma sociedade virtualizada, tecnologicamente conectada. Seus hábitos, costumes e forma de viver são diferentes das gerações anteriores, com isso facilitando as comunicações virtuais, com a mídia (MACHADO, 2010; MCCRINDLE, 2011).

A geração Z vem também com outras nomenclaturas como Zs, Zees ou Zeds, devido a essa denominação variar do termo "zapear" que é o ato de trocar de canal da televisão constantemente. Além disso, a mídia chama esta geração como a "Geração Conectada", "Geração On-line", "Geração Digital", e outras, bem como internacionalmente é conhecida como "Millennials", "New Millennials", e "C Generation" (FREIRE FILHO; LEMOS, 2008).

Diferente das outras gerações, é curioso ressaltar que quando sentem necessidade de conversar com seu superior, eles conversam com naturalidade, como se fossem um colega, devido este comportamento sem se preocupar com as consequências, faz com que queira resultados também imediatos e por isso a hierarquia vertical não faz sentido para os Z's (MENDES, 2012).

Percebe-se então, que houve não só mudança nos estudantes, mas também nas escolas, aplicando políticas públicas de incentivo à educação. Em virtude disso, torna-se importante abordar a âncoras de carreira para melhor compreensão das pretensões desses jovens da geração Z (CIRIACO, 2009).

Pode-se ressaltar também, que as características dessas gerações espelham um 
contexto histórico vivenciado por elas, existindo muitas divergências e diferentes visões no que diz respeito a pretensões de carreira de cada geração (OSWALDO, 2017).

\section{ÂNCORAS DE CARREIRA}

A teoria de âncora de carreira na visão de Chapman e Brown (2014, p. 90) "[...] tenta entender e explicar quais são os valores, necessidades e interesses que interferem nos resultados das decisões individuais e pessoais da carreira do indivíduo". No entendimento de Barth (1993, p. 90) "[...] nesta teoria, empregados e empregadores conseguem ter uma melhor visão sobre motivação".

Já para Evans (1996, p. 90) "[...] a teoria de âncora de carreira é eficaz no desenvolvimento de carreira".

Chapman e Brown (2014, p. 90) explicam que a metáfora de uma âncora empregada no entendimento do significado do termo "âncora de carreira", é utilizada para ilustrar como âncoras de carreira, mas também interferem em decisões de carreira. As âncoras de carreira são traços de personalidade estáveis que influenciam as decisões de carreira. Os autores acrescentam ainda que as pessoas têm a tendência de se afastarem de suas âncoras essenciais, centrais de carreira.

O conceito de âncora de carreira evoluiu a partir dos estudos de Schein (1977, p. 90) realizado no Massachusetts Institute of Technology (MIT)

[...] quando realizou entrevistas por um período de 10 - 12 anos após sua graduação. Seu trabalho constituiu em entrevistas focadas na história de trabalho dos participantes e as razões para suas mudanças de carreira.

Ao avaliar as respostas dos participantes, Schein (1977, p.127)

[...] notou padrões de talento, autopercepção, motivos e valores que serviriam para orientar, constranger, estabilizar e integrar a carreira da pessoa. Em uma série de estudos, identificou esses padrões então como âncora de carreira.

Schein (1978) propõe então que as funções das âncoras de carreira em forma de um quadro, do qual os indivíduos podem observar sua experiência de trabalho e determinar quais os tipos de trabalho que eles ambicionam realizar e para onde vão fazer sua maior contribuição. Podendo assim, trabalhar em direção a aumentar sua satisfação e engajamento.

Nesta perspectiva, o autor identificou a partir de suas pesquisas, cinco categorias de âncoras: 1. autonomia/Independência; 2. segurança/estabilidade; 3. competência técnica-funcional; 4. competência gerência geral; 5. criatividade empresarial. Posteriormente, Schein (1990a) adicionou três novas âncoras, sendo elas: 6. serviço ou dedicação a uma causa; 7. desafio puro; 8. estilo de vida (SCHEIN, 1990, p. 90).

Além disso, Schein (1990a) argumenta que existem oportunidades para todos os tipos de âncoras. Mas o processo de adaptação e de escolha será mais difícil e exigirá maior 
autogerenciamento da carreira. Dentro desse contexto, a teoria de âncoras de carreira é extremamente importante para alinhar com as expectativas e pretensões de carreira dos jovens, reconhecendo-se principalmente a importância desse assunto especialmente para a geração Z.

\section{DELIMITAÇÕES METODOLÓGICAS}

O método de pesquisa utilizado foi o de levantamento de campo. Através de uma pesquisa descritiva quantitativa dos dados. Utilizar-se-á como base de análise o instrumento (inventário de âncoras de carreira) proposto por Schein (1996). Destarte, o instrumento de coleta desse estudo dividiu-se em duas partes:

1. Inventário de âncoras de carreira: apresentando 42 variáveis observáveis sobre a carreira do respondente, contidas nas seguintes dimensões: vontade de servir e dedicação a uma causa; estilo de vida, segurança e estabilidade, técnica funcional, puro desafio, autonomia e interdependência, criatividade empreendedora e administrativa geral. A escala de mensuração foi composta por uma escala do tipo Likert, onde os respondentes atribuíram graus de concordância entre 1 (nunca se aplica para mim) e 6 (sempre se aplica para mim) (SCHEIN, 1996).

2. Caracterização dos respondentes (dados pessoais e ocupacionais): contendo questões relativas ao perfil, como: gênero (questão fechada com três alternativas), idade (questão aberta do tipo numérica), Estado (questão aberta) e formação (questão fechada com oito alternativas), tempo que está na empresa atual (questão aberta do tipo numérica), cargo ocupado (questão aberta), tempo que está no cargo atual (questão aberta do tipo numérica) (SCHEIN, 1996).

A coleta de dados ocorreu por meio de um questionário online, pela ferramenta Google Docs durante o mês de outubro de 2020. O formulário foi divulgado nas principais redes sociais utilizadas pelos jovens (Instagram, Facebook e WhatsApp) para que alcançasse a maior quantidade possível de público para a pesquisa. A análise dos resultados apresentados abaixo foi realizada pela acadêmica em conjunto com o sua orientadora possibilitando maior qualidade de análise e aprofundamento das informações coletadas no período.

\section{RESULTADOS}

Nesta seção são apresentados os resultados aferidos na pesquisa. 
Tabela $1-$ Perfil da amostra $(n=100)$

\begin{tabular}{|c|c|c|}
\hline \multirow{3}{*}{ Gênero } & Masculino & $32,5 \%$ \\
\hline & Feminino & $66,3 \%$ \\
\hline & Prefere não responder & $1,3 \%$ \\
\hline \multirow{2}{*}{ Estado civil } & Casado(a) / União Estável & $6,3 \%$ \\
\hline & Solteiro(a) & $93,8 \%$ \\
\hline \multirow{4}{*}{ Escolaridade } & Ensino Médio Incompleto & $58,8 \%$ \\
\hline & Ensino Médio Completo & $15 \%$ \\
\hline & $\begin{array}{l}\text { Ensino Superior Incompleto } \\
\text { Ensino Superior Completo }\end{array}$ & $\begin{array}{l}13,8 \% \\
7,5 \%\end{array}$ \\
\hline & Pós-graduação (em nível de especialização ou MBA) & $5 \%$ \\
\hline \multirow{4}{*}{ Renda Familiar } & Até 2 salários-mínimos (até $\mathrm{R} \$ 2.090,00$ ) & $45 \%$ \\
\hline & $\begin{array}{l}\text { De } 2 \text { a } 6 \text { salários mínimos (entre } R \$ 2.090,01 \text { até } R \$ \\
6.270,00 \text { ) }\end{array}$ & $48,8 \%$ \\
\hline & $\begin{array}{l}\text { De } 6 \text { a } 10 \text { salários mínimos (entre } R \$ 6.270,01 \text { até } \\
R \$ 10.450,00 \text { ) }\end{array}$ & $5 \%$ \\
\hline & Mais de 10 salários mínimos (mais de $\mathrm{R} \$ 10.450,01$ ) & $1,3 \%$ \\
\hline \multirow{6}{*}{ Profissão } & Celetista (carteira assinada) & $22,5 \%$ \\
\hline & Autônomo (a) & $1,3 \%$ \\
\hline & Empresário (a) & $3,8 \%$ \\
\hline & Estudante & $67,5 \%$ \\
\hline & Funcionário/empregado público & $2,5 \%$ \\
\hline & Estudante / não trabalha & $2,5 \%$ \\
\hline
\end{tabular}

Fonte: Autor (2020).

Nesta primeira tabela apresentamos o perfil dos respondentes, podemos analisar que $66,3 \%$ dos respondentes são do sexo feminino. Referente ao estado civil, 93,8\% são solteiros (as). Quanto a escolaridade, 58,8\% tem o ensino médio incompleto. Sobre a renda familiar, 48,8\% possuem a renda de 2 a 6 salários-mínimos e outros $45 \%$ até 2 salários-mínimos. Perguntamos ainda sobre a sua ocupação profissional, 67,5\% são estudantes.

Tabela 2 - Análise da dimensão competência técnica-funcional (TF) $(n=100)$

\begin{tabular}{|c|c|c|c|c|c|c|c|}
\hline \multirow{2}{*}{ Variável observável } & \multirow{2}{*}{ Média } & \multirow{2}{*}{$\begin{array}{l}\text { Desvio } \\
\text { Padrão }\end{array}$} & \multicolumn{5}{|c|}{ Frequência (\%) } \\
\hline & & & 1 & 2 & 3 & 4 & 5 \\
\hline $\begin{array}{l}\text { 1. Sonho em ser tão bom no que faço, de tal } \\
\text { forma que meus conhecimentos especializados } \\
\text { sejam constantemente procurados. }\end{array}$ & 4,263 & ,9105 & 1,3 & 2,5 & 16,3 & 28,7 & 51,2 \\
\hline $\begin{array}{l}\text { 9. Sinto-me sucedido em minha carreira apenas } \\
\text { quando posso desenvolver minhas habilidades } \\
\text { técnicas ou funcionais a um nível de } \\
\text { competência muito alto. }\end{array}$ & 3,225 & 1,0309 & 3,8 & 21,3 & 35,0 & 28,7 & 11,3 \\
\hline $\begin{array}{l}\text { 17. Tornar-me um gerente técnico em minha } \\
\text { área de especialização é mais atraente para } \\
\text { mim do que me tornar um gerente geral. }\end{array}$ & 3,150 & 1,0920 & 7,5 & 17,5 & 40,0 & 22,5 & 12,5 \\
\hline $\begin{array}{l}\text { 25. Sinto-me bem-sucedido na vida apenas } \\
\text { quando fui capaz de equilibrar minhas } \\
\text { necessidades pessoais, familiares e de carreira. }\end{array}$ & 2,950 & 1,2719 & 10,0 & 33,8 & 26,6 & 11,3 & 18,8 \\
\hline $\begin{array}{l}\text { 33. Sinto-me plenamente realizado em meu } \\
\text { trabalho quando sou capaz de empregar } \\
\text { minhas habilidades e talentos especiais. }\end{array}$ & 3,875 & ,9463 & 0,0 & 8,8 & 25,0 & 36,3 & 30,0 \\
\hline
\end{tabular}


Fonte: Autor (2020)

Nesta análise de competência técnica-funcional, observamos que maior parte dos respondentes possui o sonho em ser tão bom no que faz, de modo que seus conhecimentos especializados sejam constantemente procurados (média 4,26). Informam ainda, que se sentem realizados quando podem empregar suas habilidades e talentos especiais (média 3,87).

Tabela 3 - Análise da dimensão Competência gerência geral (CG) (TF) ( $n=100$ )

\begin{tabular}{|c|c|c|c|c|c|c|c|}
\hline \multirow{2}{*}{ Variável observável } & \multirow{2}{*}{ Média } & \multirow{2}{*}{$\begin{array}{l}\text { Desvio } \\
\text { Padrão }\end{array}$} & \multicolumn{5}{|c|}{ Frequência (\%) } \\
\hline & & & 1 & 2 & 3 & 4 & 5 \\
\hline $\begin{array}{l}\text { 2. Sinto-me mais realizado em meu trabalho } \\
\text { quando sou capaz de integrar e gerenciar o } \\
\text { esforço dos outros. }\end{array}$ & 3,588 & 1,0755 & 2,5 & 12,5 & 33,8 & 26,3 & 25,0 \\
\hline $\begin{array}{l}\text { 10. Sonho em dirigir uma organização } \\
\text { complexa e tomar decisões que afetem muitas } \\
\text { pessoas. }\end{array}$ & 3,088 & 1,3425 & 20,0 & 10,0 & 26,3 & 28,7 & 15,0 \\
\hline $\begin{array}{l}\text { 18. Sentir-me-ei bem-sucedido em minha } \\
\text { carreira apenas quando me tornar um gerente } \\
\text { geral em alguma organização. }\end{array}$ & 2,625 & 1,1515 & 17,5 & 32,5 & 26,3 & 17,5 & 6,3 \\
\hline $\begin{array}{l}\text { 26. Tornar-me um gerente geral é mais } \\
\text { atraente para mim do que me tornar um } \\
\text { gerente técnico em minha área de } \\
\text { especialização. }\end{array}$ & 2,600 & 1,0978 & 15,0 & 33,8 & 36,3 & 6,3 & 8,8 \\
\hline $\begin{array}{l}\text { 34. Preferiria deixar minha organização do que } \\
\text { aceitar um emprego que me afastasse da } \\
\text { trajetória de gerência geral. }\end{array}$ & 2,825 & 1,0035 & 10,0 & 25,0 & 42,5 & 17,5 & 5,0 \\
\hline Total & 2,94 & 0,790 & & & & & \\
\hline
\end{tabular}

Fonte: Autor (2020)

Na análise de competência gerência geral, grande maioria dos respondentes sentemse realizados quando são capazes de integrar e gerenciar esforços dos outros (média 3,58). Sonham também em dirigir uma organização complexa e tomar decisões que afetem muitas pessoas (média 3,08).

Tabela 4-Análise da dimensão Autonomia/independência (AI) ( $n=100)$

\begin{tabular}{|c|c|c|c|c|c|c|c|}
\hline \multirow{2}{*}{ Variável observável } & \multirow{2}{*}{ Média } & \multirow{2}{*}{$\begin{array}{l}\text { Desvio } \\
\text { Padrão }\end{array}$} & \multicolumn{5}{|c|}{ Frequência (\%) } \\
\hline & & & 1 & 2 & 3 & 4 & 5 \\
\hline $\begin{array}{l}\text { 3.Sonho em ter uma carreira que me dê a } \\
\text { liberdade de fazer o trabalho à minha maneira } \\
\text { no tempo por mim programado. }\end{array}$ & 4,138 & ,9513 & 0,0 & 7,5 & 16,3 & 31,3 & 45,0 \\
\hline $\begin{array}{l}\text { 11. Sinto-me mais realizado em meu trabalho } \\
\text { quanto tenho total liberdade de definir minhas } \\
\text { próprias tarefas, horários e procedimentos. }\end{array}$ & 3,650 & 1,0920 & 1,3 & 13,8 & 33,8 & 21,3 & 30,0 \\
\hline $\begin{array}{l}\text { 19. Sentir-me-ei bem-sucedido em minha } \\
\text { carreira apenas quando alcançar total } \\
\text { autonomia e liberdade. }\end{array}$ & 3,113 & 1,0554 & 7,5 & 17,5 & 41,3 & 23,8 & 10,0 \\
\hline $\begin{array}{l}\text { 27. Para mim, poder fazer um trabalho à minha } \\
\text { própria maneira, sem regras e restrições, é }\end{array}$ & 2,588 & 1,1329 & 18,8 & 30,0 & 31,3 & 13,8 & 6,3 \\
\hline
\end{tabular}


mais importante do que segurança.

35. Preferiria deixar minha organização do que aceitar um emprego que reduza minha $3,213 \quad 1,0755 \quad 5,0 \quad 20,0 \quad 37,5 \quad 23,8 \quad 13,8$ autonomia e liberdade.

Total $3,34 \quad 685$

Fonte: Autor (2020)

Observamos nesta análise de autonomia e independência que a maior parte dos respondentes sonham em ter uma carreira que de liberdade de fazer o trabalho da sua maneira e na sua programação de tempo (média 4,13).

Tabela 5 - Análise da dimensão Segurança/estabilidade (SE) ( $n=100)$

\begin{tabular}{|c|c|c|c|c|c|c|c|}
\hline \multirow{2}{*}{ Variável observável } & \multirow{2}{*}{ Média } & \multirow{2}{*}{$\begin{array}{l}\text { Desvio } \\
\text { Padrão }\end{array}$} & \multicolumn{5}{|c|}{ Frequência (\%) } \\
\hline & & & 1 & 2 & 3 & 4 & 5 \\
\hline $\begin{array}{l}\text { 4. Segurança e estabilidade são mais } \\
\text { importantes para mim do que liberdade e } \\
\text { autonomia. }\end{array}$ & 3,088 & 1,1821 & 12,5 & 12,5 & 43,8 & 16,3 & 15,0 \\
\hline $\begin{array}{l}\text { 12. Preferiria deixar meu emprego que aceitar } \\
\text { uma tarefa que possa colocar em risco minha } \\
\text { segurança na organização. }\end{array}$ & 3,388 & 1,2273 & 5,0 & 22,5 & 26,3 & 21,3 & 25,0 \\
\hline $\begin{array}{l}\text { 20. Procuro trabalhos em organizações que me } \\
\text { deem senso de segurança e estabilidade. }\end{array}$ & 3,750 & 1,0494 & 3,8 & 8,8 & 21,3 & 41,3 & 25,0 \\
\hline $\begin{array}{l}\text { 28. Sinto-me mais realizado em meu trabalho } \\
\text { quando percebo que tenho total segurança } \\
\text { financeira e estabilidade no trabalho. }\end{array}$ & 3,788 & 1,1103 & 1,3 & 13,8 & 25,0 & 25,0 & 35,0 \\
\hline $\begin{array}{l}\text { 36. Sonho em ter uma carreira que me dê } \\
\text { senso de segurança e estabilidade. }\end{array}$ & 3,913 & 1,0457 & 2,5 & 8,8 & 17,5 & 37,5 & 33,8 \\
\hline Total & 3,58 & ,781 & & & & & \\
\hline
\end{tabular}

Fonte: Autor (2020)

Nesta análise de segurança e estabilidade, podemos notar que grande parte dos respondentes sonham em ter uma carreira que dê a eles segurança e estabilidade (média 3,91). Informam também que sentem-se realizados em um trabalho que tenha total segurança financeira e estabilidade no trabalho (média 3,78).

Tabela 6 - Análise da dimensão Criatividade empreendedora (CE) $(n=100)$

\begin{tabular}{|c|c|c|c|c|c|c|c|}
\hline \multirow{2}{*}{ Variável observável } & \multirow{2}{*}{ Média } & \multirow{2}{*}{$\begin{array}{l}\text { Desvio } \\
\text { Padrão }\end{array}$} & \multicolumn{5}{|c|}{ Frequência (\%) } \\
\hline & & & 1 & 2 & 3 & 4 & 5 \\
\hline $\begin{array}{l}\text { 5. Estou sempre procurando ideias que me } \\
\text { permitam iniciar meu próprio negócio. }\end{array}$ & 3,513 & 1,0554 & 3,8 & 12,5 & 31,3 & 33,8 & 18,8 \\
\hline $\begin{array}{l}\text { 13. Montar meu próprio negócio é mais } \\
\text { importante para mim do que atingir uma alta } \\
\text { posição gerencial como empregado. }\end{array}$ & 2,850 & 1,2232 & 15,0 & 25,0 & 32,5 & 15,0 & 12,5 \\
\hline $\begin{array}{l}\text { 21. Sinto-me realizado em minha carreira } \\
\text { quando tenho a oportunidade de construir } \\
\text { alguma coisa que seja resultado unicamente de } \\
\text { minhas próprias ideias e esforços. }\end{array}$ & 3,525 & 1,2322 & 2,5 & 22,5 & 27,5 & 15,5 & 32,5 \\
\hline $\begin{array}{l}\text { 29. Sinto-me bem-sucedido em meu trabalho } \\
\text { apenas quando posso criar ou construir alguma }\end{array}$ & 3,025 & 9933 & 5,0 & 23,8 & 43,8 & 18,8 & 8,8 \\
\hline
\end{tabular}




\begin{tabular}{llllllll}
\hline coisa que seja inteiramente de minha autoria. & & & & & & & \\
\hline $\begin{array}{l}\text { 37. Sonho em iniciar e montar meu próprio } \\
\text { negócio. }\end{array}$ & 3,525 & 1,2424 & 7,5 & 12,5 & 28,7 & 22,5 & 28,7 \\
\hline Total & 3,28 &, 776 & & & & & \\
\hline
\end{tabular}

Fonte: Autor (2020)

Nesta análise de criatividade empreendedora, podemos observar que os respondentes sonham em montar seu próprio negócio (média 3,52). Sentem-se também realizados quando tem a oportunidade de construir alguma coisa que seja resultado das próprias ideias e esforços (média 3,52).

Tabela 7 - Análise da dimensão Senso de dever /dedicação a uma causa (SD) ( $n=100$ )

\begin{tabular}{|c|c|c|c|c|c|c|c|}
\hline \multirow{2}{*}{ Variável observável } & \multirow{2}{*}{ Média } & \multirow{2}{*}{$\begin{array}{l}\text { Desvio } \\
\text { Padrão }\end{array}$} & \multicolumn{5}{|c|}{ Frequência (\%) } \\
\hline & & & 1 & 2 & 3 & 4 & 5 \\
\hline $\begin{array}{l}\text { 6. Sinto-me bem em minha carreira apenas } \\
\text { quando tenho a sensação de ter feito uma } \\
\text { contribuição real para o bem da sociedade. }\end{array}$ & 3,513 & 1,2012 & 5,0 & 17,5 & 25,0 & 26,3 & 26,3 \\
\hline $\begin{array}{l}\text { 14. Sinto-me mais realizado em minha carreira } \\
\text { quando posso utilizar meus talentos a serviço } \\
\text { dos outros. }\end{array}$ & 3,813 & 1,0919 & 0,0 & 15,0 & 25,0 & 23,8 & 36,3 \\
\hline $\begin{array}{l}\text { 22. Utilizar minhas habilidades para tornar o } \\
\text { mundo um lugar melhor para se viver e } \\
\text { trabalhar é mais importante para mim do que } \\
\text { alcançar uma posição gerencial de alto nível. }\end{array}$ & 3,550 & 1,2107 & 5,0 & 13,8 & 33,8 & 16,3 & 31,3 \\
\hline $\begin{array}{l}\text { 30. Sonho em ter uma carreira que faça uma } \\
\text { real contribuição à humanidade e à sociedade. }\end{array}$ & 3,838 & 1,1188 & 1,3 & 13,8 & 22,5 & 25,0 & 37,5 \\
\hline $\begin{array}{l}\text { 38. Preferiria deixar minha organização do que } \\
\text { aceitar uma tarefa que prejudique minha } \\
\text { capacidade de servir aos outros. }\end{array}$ & 3,163 & 1,1632 & 8,8 & 18,8 & 35,0 & 22,5 & 15,0 \\
\hline Total & 3,57 & 794 & & & & & \\
\hline
\end{tabular}

Fonte: Autor (2020)

Nesta análise de senso de dever e dedicação a uma causa, observamos que eles sonham em ter uma carreira que contribua à humanidade e sociedade (média 3,83). Sentemse realizados quando podem utilizar seus talentos e serviços dos outros (média 3,81).

Tabela 8 - Análise da dimensão desafio puro (DP) $(n=100)$

\begin{tabular}{|c|c|c|c|c|c|c|c|}
\hline \multirow{2}{*}{ Variável observável } & \multirow{2}{*}{ Média } & \multirow{2}{*}{$\begin{array}{l}\text { Desvio } \\
\text { Padrão }\end{array}$} & \multicolumn{5}{|c|}{ Frequência (\%) } \\
\hline & & & 1 & 2 & 3 & 4 & 5 \\
\hline $\begin{array}{l}\text { 7.Sonho com uma carreira na qual eu possa } \\
\text { solucionar problemas ou vencer com situações } \\
\text { extremamente desafiadoras }\end{array}$ & 3,900 & 1,0862 & 3,8 & 7,5 & 18,8 & 35,0 & 35,0 \\
\hline $\begin{array}{l}\text { 15.Sinto-me realizado em minha carreira } \\
\text { apenas quando enfrento e supero desafios } \\
\text { extremamente difíceis. }\end{array}$ & 3,250 & 1,1418 & 6,3 & 18,8 & 36,3 & 21,3 & 17,5 \\
\hline $\begin{array}{l}\text { 23.Sinto-me mais realizado em minha carreira } \\
\text { quando solucionei problemas insolúveis ou } \\
\text { venci o que aparentemente era impossível de } \\
\text { ser vencido. }\end{array}$ & 3,763 & 1,1165 & 2,5 & 13,8 & 20,0 & 32,5 & 31,3 \\
\hline
\end{tabular}




\begin{tabular}{lrrrrrrr}
\hline $\begin{array}{l}\text { 31. Procuro oportunidades de trabalho que } \\
\text { desafiem fortemente minhas habilidades para } \\
\text { solucionar problemas. }\end{array}$ & 3,588 & 1,0274 & 2,5 & 10,0 & 36,3 & 28,7 & 22,5 \\
\hline $\begin{array}{l}\text { 39. Trabalhar em problemas praticamente } \\
\text { insolúveis para mim é mais importante do que } \\
\text { alcançar uma posição gerencial de alto nível. }\end{array}$ & 2,800 & 1,2263 & 15,0 & 28,7 & 30,0 & 13,8 & 12,5 \\
\hline $\begin{array}{l}\text { Total } \\
\text { 3,46 }\end{array}$ & ,764 & & & & & \\
\hline
\end{tabular}

Fonte: Autor (2020)

Nesta análise de desafio puro, estes jovens sonham com uma carreira na qual possam solucionar problemas ou vencer situações desafiadoras (média 3,9). Sentem-se realizado quando solucionam problemas que aparentemente eram impossíveis (média 3,76).

Tabela 9 - Análise da dimensão estilo de vida (EV) $(n=100)$

\begin{tabular}{|c|c|c|c|c|c|c|c|}
\hline \multirow{2}{*}{ Variável observável } & \multirow{2}{*}{ Média } & \multirow{2}{*}{$\begin{array}{l}\text { Desvio } \\
\text { Padrão }\end{array}$} & \multicolumn{5}{|c|}{ Frequência (\%) } \\
\hline & & & 1 & 2 & 3 & 4 & 5 \\
\hline $\begin{array}{l}\text { 8. Preferiria deixar meu emprego do que ser } \\
\text { colocado em um trabalho que comprometa } \\
\text { minha capacidade de me dedicar aos assuntos } \\
\text { pessoais e familiares. }\end{array}$ & 3,175 & 1,1989 & 11,3 & 16,3 & 30,0 & 28,7 & 13,8 \\
\hline $\begin{array}{l}\text { 16. Sonho com uma carreira que me permita } \\
\text { integrar minhas necessidades pessoais, } \\
\text { familiares e de trabalho. }\end{array}$ & 3,775 & 1,1135 & 3,8 & 10,0 & 22,5 & 32,5 & 31.3 \\
\hline $\begin{array}{l}\text { 24. Sinto-me bem-sucedido na vida apenas } \\
\text { quando fui capaz de equilibrar minhas } \\
\text { necessidades pessoais, familiares e de carreira. }\end{array}$ & 3,625 & 1,1733 & 6,3 & 10,0 & 26,3 & 30,0 & 27,5 \\
\hline $\begin{array}{l}\text { 32.Equilibrar as exigências da minha vida } \\
\text { pessoal e profissional é mais importante do } \\
\text { que alcançar alta posição gerencial. }\end{array}$ & 3,513 & 1,1473 & 6,3 & 11,3 & 30,0 & 30,0 & 22,5 \\
\hline $\begin{array}{l}\text { 40. Sempre procurei oportunidades de } \\
\text { trabalho que minimizassem interferências com } \\
\text { assuntos pessoais e familiares. }\end{array}$ & 3,163 & 1,1301 & 11,3 & 12,5 & 35,0 & 31,3 & 10,0 \\
\hline Total & 3,45 & ,800 & & & & & \\
\hline
\end{tabular}

Fonte: Autor (2020)

Nesta análise de estilo de vida, notamos que esta geração sonha com uma carreira que permita integrar suas necessidades pessoais, familiares e de trabalho (média 3,77). Observa-se também que se sentem bem-sucedidos na vida apenas quando são capazes de equilibrar suas necessidades pessoais, familiares e de carreira (média 3,62).

\section{CONSIDERAÇÕES FINAIS}

Após a análise dos resultados da pesquisa, juntamente com o apresentado na fundamentação teórica acima pode-se afirmar que todos os objetivos da pesquisa foram alcançados, assim como a pergunta-problema foi respondida no decorrer do artigo, tendo em vista as informações coletadas e a pesquisa teórica em sites acadêmicos como Scielo e livros 
sobre o tema. Conclui-se então que na geração Z, com base nos resultados dos 100 jovens respondentes, as principais âncoras de carreira são: Análise da dimensão competência técnicafunciona (média 3,49); Análise da dimensão segurança e estabilidade (média 3,58); Análise da dimensão senso de dever e dedicação a uma causa (média 3,57); Análise da dimensão desafio puro (média 3,46).

Pode-se observar que eles almejam serem bons no que fazem a ponto de serem constantemente procurados pelo mercado de trabalho, buscando assim uma carreira que dê a eles segurança e estabilidade, solucionando problemas e situações desafiadoras. Sentem-se realizados quando puderem empregar suas habilidades e talentos, solucionando problemas que aparentemente impossíveis em um trabalho que tenha total segurança financeira e estabilidade. Estes jovens da geração $Z$ com faixa etária até 24 anos e que foram os sujeitos de estudo, são em geral estudantes e nem se quer ingressaram no mercado de trabalho, mesmo assim demonstram capacidade de falar e planejar sobre o futuro profissional.

A geração Z busca alcançar o topo, é uma geração determinada, tecnológica, buscando sempre novas perspectivas de vida, sendo as âncoras de carreiras obstáculos para seu desenvolvimento profissional, mas também podem ser elementos facilitadores. A teoria de Schein (1996) possibilitou muitos desdobramentos no campo da psicologia e da gestão de recursos humanos, e para fins acadêmicos aqui buscados.

As ancoras de carreira tem norteado muito mais as pessoas, tratando-se aqui da geração Z. Isto é compreensível quando olhamos para a definição de ancoras de carreira, sendo cabível aos jovens dessa geração a busca pelo "mais", mesmo que muitas vezes possuindo desigualdades sociais, seu empenho vem se desenvolvendo diferentemente em relação às gerações anteriores.

Por fim, constata-se que a temática ainda demanda muitas pesquisas, com emprego de metodologias diversas, para que se possa construir uma construção mais abrangente sobre a temática. Esse aprofundamento é fundamental para que essa geração possa ser melhor compreendida, de modo a desenvolver ações de auxílio a estes sujeitos, bem como estratégias organizacionais mais alinhadas às características da geração Z. Análises muito pertinentes podem ser realizadas, por exemplo, confrontando dados sobre a geração $Z$ com as teorias sociológicas mais recentes, tais como as ideias de Bauman sobre a liquidez da modernidade ou então Byung Chul Han sobre a sociedade da transparência e do cansaço.

\section{REFERÊNCIAS}

BARTH, T.L. Career anchor theory. Review of Public Personnel Administration, v. 13, n. 4, p. 27-42, 1993

BECKER, F. Os conflitos de gerações na comunicação para o público interno. 2016. Disponível 
em: https://pt.linkedin.com/pulse/os-conflitos-de-gera\%C3\%A7\%C3\%B5es-na-

comunica\%C3\%A7\%C3\%A3o-para-o-p\%C3\%BAblico-fabiana-becker. Acesso em 01 nov. 2020.

BOLDRINI, B.C.; LUCENA, W.L. Os desafios enfrentados pelas organizações atuais pela inserção da geração " $Z$ " no mercado de trabalho. Destarte, Vitória, v.4, n.2, p. 45-63, out. 2014.

CHAPMAN, J.R.; BROWN, B.L. An empirical study of the career anchors that govern career Decisions. Personnel Review, v. 43, n. 5 p. 717-740, 2014.

CIRIACO, Douglas. O que é a Geração Z? Tec Mundo, 2009. Disponível em:

https://www.tecmundo.com.br/curiosidade/2391-o-que-e-a-geracao-z-.htm. Acesso em 30 out. 2020.

FAGUNDES, M. M. Competência Informacional e Geração Z: um estudo de caso de duas escolas de Porto Alegre. 2011. Trabalho de Conclusão de curso biblioteconomia, da Faculdade de Biblioteconomia e Comunicação da Universidade Federal do Rio Grande do Sul. Porto Alegre, 2011.

LEVENFUS, R. S. Geração Zapping e o sujeito da orientação vocacional. In: LEVENFUS, R. S.; SOARES, D. H. P. Orientação vocacional/ocupacional, novos achados teóricos, técnicos e instrumentais para a clínica, a escola e a empresa. Porto Alegre: Artmed, 2002.

MACHADO, V. B. Diferentes porém iguais. 2010. Disponível em:

http://www.contee.org.br/noticias/artigos/art508.asp. Acesso em: 30 out. 2020.

McCRINDLE, M. The ABC of the XYZ: Understanding global Generations. Sydney: UNSW Press, 2011.

MEDEIROS, C. A. F. Comprometimento organizacional: Um estudo de suas relações com características organizacionais e desempenho nas empresas hoteleiras. 2003. (Tese de doutorado). Universidade de São Paulo. São Paulo, 2003.

MENDES, T. Geração Y: forjada pelas novas tecnologias. RBA - Revista Brasileira de Administração. São Paulo, n. 91, p. 52-54, nov./dez. 2012.

OBREGON, Sandra Leonara et al. Geração z: compreendendo as aspirações de carreira de estudantes de escolas públicas e privadas. Revista de Administração. v. 15, n. 26, p. 84-108, dez. 2016.

RODRIGUES, A. C. L.; BORMIO, S. N. G. Escolha profissional: tarefa complexa na adolescência. In: II Simpósio Internacional de Educação Linguagens Educativas: perspectivas interdisciplinares na atualidade, Bauru/SP, 2008.

SCHEIN, E. H. Career anchors and career paths: A panel study of management school graduates. In: MAANEN, J. Van (Ed.). Organizational careers: Some new perspectives. London: John Wiley, 1977. 
SCHEIN, E.H. Career dynamics: matching individual and organizational needs. Reading, MA: Addison- Wesley.1978.

SCHEIN, Edgar, H. Identidade profissional: como ajustar suas inclinações a suas opções de trabalho. Tradução de Margarida D. Black. São Paulo: Nobel, 1996.

SERRANO, Daniel Portillo. Geração Z. 2010. Disponível em:

http://www.portaldomarketing.com.br/Artigos3/Geracao_Z.htm. Acesso em 05 nov. 2020.

VELOSO, E.F.R.; DA SILVA, R.C.; DUTRA, J. S. Gerações e Carreira: A Relação entre as Percepções sobre Carreiras Inteligentes e sobre Crescimento Profissional nas Organizações. In: XXXV Encontro da ANPAD. Rio de Janeiro. Anais eletrônicos. Rio de Janeiro: ANPAD, 2011. 